
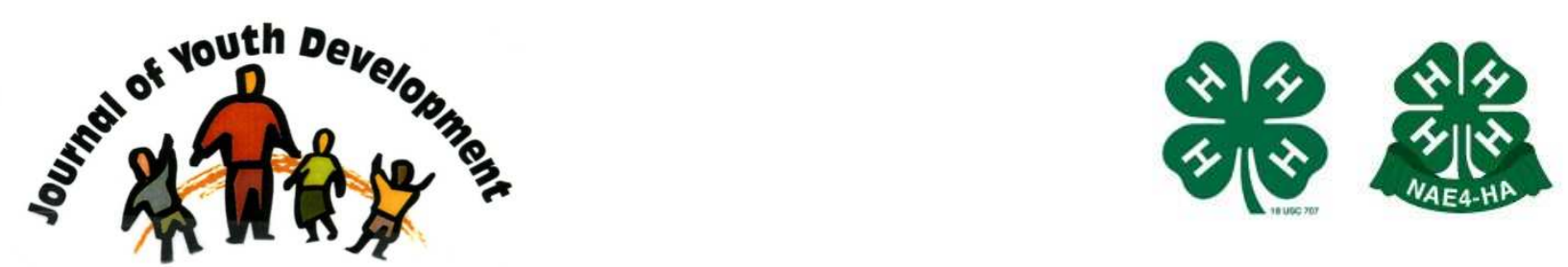

Bridging Research \& Practice

\title{
Character Development among Youth of Color from Low-SES Backgrounds: An Examination of Boy Scouts of America's ScoutReach Program
}

\author{
Kaitlyn A. Ferris \\ Tufts University \\ kaitlyn.ferris@tufts.edu \\ Rachel M. Hershberg \\ University of Washington Tacoma \\ Shaobing Su \\ Tufts University \\ Jun Wang \\ Tufts University \\ Richard M. Lerner \\ Tufts University
}

Note: The preparation of this article was supported in part by grants from the John Templeton Foundation. Correspondence should be addressed to Kaitlyn A. Ferris: Institute for Applied Research in Youth Development, 26 Winthrop Street, Tufts University, Medford, MA 02155, USA. Email: kaitlyn.ferris@tufts.edu 


\title{
JOURNAL OF YOUTH DEVELOPMENT \\ bridging research and practice

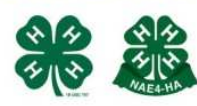

Volume 10, Number 3, Special Issue 2015

Article 151003FA002

\section{Character Development among Youth of Color from Low-SES Backgrounds:}

\section{An Examination of Boy Scouts of America's ScoutReach Program}

\author{
Kaitlyn A. Ferris \\ Tufts University \\ Rachel M. Hershberg \\ University of Washington Tacoma \\ Shaobing Su, Jun Wang, and Richard M. Lerner \\ Tufts University
}

\begin{abstract}
This study examined character attributes associated with participation in ScoutReach, Boy Scouts of America's recent program innovation created to deliver Scouting curriculum to underserved populations. Participants were predominantly Black/African American (72.9\%; $\left.N=266, M_{\text {age }}=10.54, S D=1.58\right)$ and resided in lowincome urban communities. Youth completed surveys assessing how much they embody different character attributes (e.g., kindness, helpfulness, hopeful future expectations), and a subset of youth ( $n=$ 22) also participated in semi-structured interviews examining character-shaping experiences within the program. Results replicated an eight-factor character structure established with youth involved in traditional Scouting programs, and indicated that involvement in ScoutReach may positively contribute to the development in youth of prosocial behaviors, future career goals, tolerance beliefs, and the manifestation of character attributes across Scouting and nonScouting contexts. Together, these findings have implications for measuring character constructs among youth of color from low-SES backgrounds, and for the conduct of youth-serving character development programs more generally.
\end{abstract}




\section{Introduction}

Boy Scouts of America (BSA) represents a major out-of-school time (OST) program whose mission is to develop character attributes in youth that will help them become engaged citizens who make positive contributions to society (Hilliard et al., 2014). Through Scouting, youth participate in skillbuilding and leadership activities in nature, which are believed to contribute to their character development (Jang et al., 2012; Polson et al., 2013). The few studies focusing specifically on the impact of Scouting indicate that involvement in BSA programming during childhood may contribute to higher levels of social capital and greater community engagement during adulthood, especially among youth participating in the program at the highest levels (i.e., Eagle Scouts) and for more than five years (Harris Interactive, 2005; Polson et al., 2013).

Despite the noted benefits of BSA participation, youth of color from low-socioeconomic status (SES) backgrounds are typically underrepresented in traditional forms of Scouting (Pedersen \& Seidman, 2005). This situation corresponds to participation rates in other major OST programs (Lareau, 2003). The absence of such experiences for these youth is unfortunate, given that the existence of external support systems in community and school settings has been shown to promote positive development and to decrease vulnerability to negative outcomes (Richardson et al., 2014).

More research is needed on the OST programs in which diverse youth participate, especially during middle childhood. Research on program experiences for these youth, and during this period of development, is necessary because there are few studies that explicitly highlight the character strengths of young boys of color in middle childhood (Cabrera, 2013). In addition, young boys, especially youth of color from low-SES urban communities, face many barriers to being viewed as enacting acceptable male behavior in today's society (Zimbardo \& Duncan, 2012). As such, some OST programs may represent key ecological assets in the lives of young boys of color. These programs may provide resources that enable boys to enhance their development of specific character attributes (e.g., helpfulness, trustworthiness, hopeful future expectations), connect them to adult leaders who recognize their development of such attributes, and predict indicators of thriving well into adulthood (e.g., college attendance, civic engagement; Vandell et al., 2015).

To begin addressing these gaps in research, this study examined character development among youth in ScoutReach programs in greater Philadelphia. ScoutReach was created in 1998 to deliver Scouting curricula to youth who have historically been the "hardest to reach" and to include in BSA programs, specifically youth of color residing in urban communities throughout the U.S. (Hershberg et al., 2015). ScoutReach, as with traditional BSA, strives to promote character attributes, responsible citizenship, and the development of skills that can be applied across contexts.

However, the Scouting experience does differ, to a certain extent, for youth involved in ScoutReach as meetings typically occur directly after school (compared to during the evenings or on weekends); packs are led by paid staff members (often teachers employed by the school where meetings take place); and parents have minimal involvement in the planning or execution of Scouting curricula. ScoutReach leaders may develop innovative ways to deliver programming in order to overcome financial and environmental disparities of their packs, including limited access to natural environments, such as national parks or forests, in the urban settings where their meetings are held (Hershberg et al., 2015). Despite program growth (over 3,000 youth participate in ScoutReach in Philadelphia alone; D. Irizarry, personal communication, August 21, 2014), little research has investigated youth experiences within the program, or how these experiences may contribute to the development of character attributes. Specific experiences within ScoutReach may contribute to 
character, and to positive youth development (PYD), in distinct ways, and such development may influence other contexts (e.g., school, family) (Lerner et al., 2015).

The relational developmental systems (RDS; Overton, 2015) metatheory, and the PYD perspective (Lerner et al., 2015) linked to RDS metatheory, provide useful frameworks for examining the experiences of youth in ScoutReach programs. When applying the RDS-PYD theoretical framework to youth in ScoutReach contexts, development is viewed as occurring through mutually beneficial person $\longleftrightarrow \rightarrow$ context relations between ScoutReach youth, the OST program context, and additional settings relevant in the lives of youth (e.g., school).

Examination of ScoutReach youth program experiences from this perspective may provide a better understanding of how individual attributes (e.g., hopeful future expectations) among an understudied population of youth, may interact with characteristics of the OST program environment (e.g., adult mentors, activities in nature; Hershberg et al., 2015) to impact the development of character attributes. Given pervasive racial inequalities in the U.S., and the negative depictions of youth of color in the media (Adams-Bass et al., 2014), research detailing the strengths and positive experiences of young boys of color in urban communities, and the ecological resources in their lives (e.g., OST programs), is timely.

Accordingly, a mixed-methods design, involving simultaneous quantitative-qualitative methods, was employed to begin investigating the structure and content of character attributes among ScoutReach youth (Creswell \& Plano-Clark, 2011; Johnson et al., 2015). First, the factor structure of ScoutReach youth character attributes was compared to a character factor structure derived from scores on a measure developed with youth participating in (a) traditional Scouting programs (e.g., primarily White youth from middle-class backgrounds) and (b) boys and girls from comparable SES backgrounds (Wang et al., 2015b).

Importantly, we note that interindividual variability in quantitative survey responses may be underestimated in large-scale, group-level analyses due to the use of statistical methods predicated on the ergodic theorem (i.e., involving the assumption of homogeneity and stationarity; Molenaar \& Nesselroade, 2015). Therefore, we analyzed qualitative interviews to identify potential interindividual differences and variations in the content of descriptions of character-related experiences in and outside of ScoutReach (Denzin \& Lincoln, 2005; Creswell \& Plano-Clark, 2011). We also drew on qualitative interview data to investigate potential associations between character attributes discussed by participants and their descriptions of ScoutReach program experiences. Because of the unique characteristics of the sample, and the relative absence of research focusing on positive attributes among ethnic-minority youth (Fredricks \& Simpkins, 2012; for exceptions, see Dawes \& Larson, 2011; Simpkins et al., 2011), this study also highlighted other positive ecological assets identified in the lives of ScoutReach youth.

\section{Method}

\section{Participants}

Youth were recruited from ScoutReach programs based in the Philadelphia-area, Cradle of Liberty (COL) Council. Data were collected between October 1, 2012 and March 1, 2015. The overall sample was comprised of 266 youth $\left(M_{\text {age }}=10.54, S D=1.58\right.$, Range $=6.27-14.13$ years, $72.9 \%$ African American/Black). The mixed-methods sample of youth ( $n=22 ; 8.3 \%$ of the total sample), who completed both quantitative survey measures and a qualitative interview, was nested within the larger sample of Scouts who only completed quantitative survey measures $(n=244 ; 91.7 \%$ of the total sample). Participants in the larger sample and the mixed-methods sample were selected based 
on convenience sampling at ScoutReach pack meetings and Scout camps within the COL Council. In order to create the mixed-methods sample, interviews were conducted during several visits to Scout day camp. Specifically, a team of seven researchers were given permission to conduct 20-minute interviews with Scouts during four days of summer camp, and 22 interviews were conducted with ScoutReach youth. No significant age differences existed between ScoutReach youth in the larger sample $\left(M_{\text {age }}=10.52, S D=1.60\right)$ and the mixed-methods sample $\left(M_{\text {age }}=10.76, S D=1.38\right)$. All youth in the mixed-methods sample were African American/Black. In the sample of youth participating in the quantitative assessment $(n=244), 67.79 \%$ were African American/Black, $\mathrm{X}^{2}(3, N$ $=155)=8.54, p=.04$.

\section{Quantitative Survey Measures}

Youth completed the Assessment of Character in Childhood and Early Adolescence (ACCEA), which includes subscales informed by BSA's character-based mission (Wang et al., 2015b). Items were scored using a 5-point Likert scale with values ranging from 1 (Not at all like me) to 5 (Exactly like $m e)$, and higher scores indicated that Scouts possessed higher levels of each character attribute. All items were adapted for use with participants as young as six years old. Sample items and reliabilities for each subscale are reported below.

Obedience. Four items ( $a=.68$ ) assessed rule following (e.g., "I do what my teachers say"). Religious reverence. Four items $(a=.67)$ examined involvement in faith-based practices (e.g., "I pray").

Cheerfulness. Three items $(a=.74)$ measured participants' self-reported degree of happiness (e.g., "I am happy").

Kindness. Four items $(a=.77)$ assessed kindness toward others (e.g., "I'm kind to other kids").

Thriftiness. Four items $(a=.64)$ measured conservation of resources (e.g., "I save my money for something special").

Trustworthiness. Five items assessed honesty and responsibility (e.g., "I can be counted on to tell the truth").

Helpfulness. Six items $(a=.79)$ measured engagement in prosocial behaviors (e.g., "I help my friends").

Hopeful future expectations. Three items $(a=.59)$ assessed hopeful future expectations (e.g., "I will have a happy family").

\section{Qualitative Interview Protocols}

A semi-structured interview protocol was developed to generate more information about youth experiences in ScoutReach programs and character attributes assessed quantitatively (Creswell \& Plano-Clark, 2011). Specifically, youth were asked to describe their experiences in ScoutReach and about what specific character attributes meant to them (e.g., kindness). They were also asked about their interactions and relationships with program leaders. Sample questions included: "Since you joined Cub Scouts, what are some things you learned?" and "What do you like most about your pack leaders?" Questions about positive attributes that were not assessed quantitatively, but seemed relevant to the Scouting context, were also asked (e.g., "Should all boys be allowed to join Cub Scouts?" was asked to explore tolerance).

\section{Procedure}

Pack leaders from across the COL Council recruited participants to complete quantitative survey measures. Survey completion took approximately 15 minutes, and each Scout was incentivized with a $\$ 20$ gift card. In addition, youth were recruited at summer camps to participate in interviews investigating experiences within ScoutReach. Interviews were, on average, 15 minutes in length, 
audio-recorded, and transcribed by the research team. Youth completing an interview received an additional \$20 gift card. All participating youth had parental consent and provided youth assent prior to survey completion/being interviewed.

\section{Analytic Strategy}

Analyses were conducted on a cross-sectional sample derived from five waves of data comprising a larger, longitudinal mixed-methods study (Hilliard et al., 2014). Because longitudinal participants entered the study at different waves, only the first wave of data provided by each participant was included in the current analyses.

\section{Quantitative Analyses}

Confirmatory factor analysis in MPlus Version 7 was used to examine whether the factor structure of character attributes among ScoutReach youth replicated previous findings with youth enrolled in traditional forms of Scouting and boys and girls from comparable SES backgrounds (Wang et al., 2015b). Accordingly, following the analytic strategy undertaken by Wang et al. (2015b), we compared three competing measurement models of the ACCEA, including:

1. A one-factor model with all items loading onto one higher-order character factor;

2. An eight-factor character model; and

3. A second-order factor model with a higher-order latent construct of character accounting for covariances among the eight first-order character attributes.

In all models, cut-off values for model fit statistics outlined by Hooper and colleagues (2008) were used to distinguish a well-fitting model. The MLR estimator in MPlus was used to account for nonnormality in the data. In order to compare nested measurement models, adjusted chi-square statistics $\left(S-B X^{2}\right)$ and corrected chi-square difference tests $\left(\triangle S-B X^{2}\right)$ were used following procedures outlined by Satorra and Bentler (1999) to identify the best fitting model.

\section{Qualitative Analyses}

A directed content analysis of youth interviews in NVivo 10 software was conducted to identify salient program experiences and character attributes described by ScoutReach youth (Bazeley \& Jackson, 2013). This approach was selected over others because RDS-based models of character development in OST programs (Hershberg et al., 2015) informed analyses. This theoretical model was extended by focusing specifically on potential character development experiences of youth in ScoutReach programs (Hsieh \& Shannon, 2005).

The first and third authors immersed themselves in the data by independently reviewing 22 transcripts and developing a list of preliminary content codes relevant to character development in OST programs (Hsieh \& Shannon, 2005). Codes were created to represent attributes that appeared across several transcripts and to capture resources participants identified as part of ScoutReach (and, to a lesser degree, non-ScoutReach) settings related to the development of such attributes (e.g., role models). The authors created a codebook outlining definitions for each code, and used Nvivo 10 software to double-code three interviews. After the first round of coding, the first, second, and third authors met to discuss the application of the codebook and areas of disagreement. Codebook adjustments (e.g., including more interview context; Bazeley \& Jackson, 2013) were made, and the first and third authors re-coded transcripts and achieved an acceptable inter-rater reliability rating (kappa = .74; Gwet, 2014). The remaining 19 interviews were then divided and coded using the 
updated codebook. Content codes appearing consistently across transcripts were also examined for variability across youth.

Findings are first organized by the main character attribute identified, noting variability in descriptions of this attribute and the ScoutReach experiences potentially contributing to this attribute. Then, findings related to additional experiences in the lives of youth (e.g., experiences with role models) that appeared to be connected to their ScoutReach experiences, and to the character attributes assessed in this study, are presented. Pseudonyms are used throughout the discussion of the results to protect participants' identities.

\section{Results}

As noted in Table 1, all character attributes were significantly and positively correlated. Age and race were not significantly correlated with character attributes. Mean scores on character attributes were compared across the larger sample $(n=244)$ and the mixed-methods sample $(n=22)$ to ensure that findings from mixed-methods analyses could be generalized to the larger ScoutReach sample. No significant differences between the two groups emerged. Data were also examined for missingness and distribution properties. Although the percentage of missing data ranged from $4.0 \%$ to $9.8 \%$ per scale item, and items were negatively skewed (i.e., positivity bias) for all youth, no missing values were imputed and all cases were retained because full information maximum likelihood estimation was used to provide unbiased parameter estimates (Wothke, 2000).

Table 1

Descriptive Statistics and Correlations for Key Study Variables

\begin{tabular}{|l|c|c|c|c|c|c|c|c|}
\hline & 1 & 2 & 3 & 4 & 5 & 6 & 7 & 8 \\
\hline 1. Obedience & - & & & & & & & \\
\hline 2. Reverence & $.26 * * *$ & - & & & & & & \\
\hline 3. Cheerfulness & $.31^{* * *}$ & $.19^{* *}$ & - & & & & & \\
\hline 4. Kindness & $.49^{* * *}$ & $.42^{* * *}$ & $.52^{* * *}$ & - & & & & \\
\hline 5. Thriftiness & $.42^{* * *}$ & $.37^{* * *}$ & $.32^{* * *}$ & $.42^{* * *}$ & - & & & \\
\hline 6. Trustworthiness & $.48^{* * *}$ & $.27^{* * *}$ & $.39^{* * *}$ & $.53^{* * *}$ & $.48^{* * *}$ & - & & \\
\hline 7. Helpfulness & $.31^{* * *}$ & $.39^{* * *}$ & $.42^{* * *}$ & $.63^{* * *}$ & $.49 * * *$ & $.56 * * *$ & - & \\
\hline $\begin{array}{l}\text { 8. Hopeful future } \\
\text { expectations }\end{array}$ & $.33^{* * *}$ & $.34^{* * *}$ & $.41^{* * *}$ & $.51^{* * *}$ & $.36 * * *$ & $.61^{* * *}$ & $.53^{* * *}$ & - \\
\hline Mean & 4.06 & 4.04 & 4.00 & 4.07 & 3.85 & 4.05 & 4.14 & 4.45 \\
\hline Standard Deviation & .72 & .88 & .93 & .84 & .87 & .78 & .75 & .63 \\
\hline
\end{tabular}

Note. ${ }^{* *} p<.01,{ }^{* * *} p<.001$. 


\section{The Factor Structure of Character Attributes}

First, a one-factor model with all items loading onto one higher-order character factor was examined. All items loaded significantly, and had moderate to strong loadings ${ }^{1}$. The fit indices in this model were: $X^{2}(495)=1015.66, p<.001, \mathrm{CFI}=.75, \mathrm{TLI}=.73, \mathrm{RMSEA}=.06, \mathrm{SRMR}=.07$. Similar to Wang and colleagues (2015b), the CFI and TLI fit indices failed to meet the recommended cut-off values, indicating that a unidimensional character factor was not supported.

In the second model, an eight-factor character model was tested. The hypothesized model fit the data well $\left(X^{2}(467)=677.17, p<.001, \mathrm{CFI}=.90, \mathrm{TLI}=.88\right.$, RMSEA $=.04$, SRMR $\left.=.06\right)$. Factor loadings were moderate to strong, and all items loaded significantly. As Model 1 is nested within Model 2, a corrected chi-square difference test was used to compare fit indices between these models. The eight-factor character model provided a significant improvement in fit when compared to the one-factor model, $\Delta S-B(28)=338.49, p<.001$. The eight latent constructs representing each character attribute were also moderately to strongly correlated ( $/ \mathrm{s}=.25-.92$ ).

Finally, we tested a third model, that is, a higher-order latent construct representing youth overall character, which accounted for high correlations among the eight character attributes. This model fit the data well and all eight first-order latent constructs loaded at moderate to strong levels (.56-.91). The fit indices in this model were: $X^{2}(487)=729.06, p<.001, \mathrm{CFI}=.88, \mathrm{TLI}=.87$, RMSEA $=.04$, SRMR $=.06$. However, results of a chi-square difference test indicated that this model provided a significant decrease in model fit, $\Delta S-B(20)=51.89, p<.001$, compared to the eight-factor model, within which Model 3 is nested. Thus, similar to Wang and colleagues' (2015b), the eight-factor character model provided the best fit for ScoutReach youth character attributes.

\section{Qualitative Analyses of Youth Program Experiences and Character Attributes}

In interviews, ScoutReach youth consistently described character attributes of kindness, helpfulness, and hopeful future expectations, and provided multiple examples of how they enacted these attributes and/or of what these attributes mean to them (i.e., these attributes appeared in $100 \%$, $91 \%$, and $95 \%$ of interviews, respectively). In examples indicating hopeful future expectations, 15 youth $(68 \%)$ also described commitments they developed to positively impacting their communities, and how ScoutReach activities and important role models in their lives, influenced such commitments. Finally, tolerance also appeared to be an important attribute among all participants, and one that could be associated with features of ScoutReach that distinguish it from traditional Scouting.

Kindness. All youth provided definitions of kindness and examples of how they exhibit kindness. Definitions of kindness varied, and included references to sharing, being nice to others, and sticking up for one's friends. Some youth also described kindness in terms of what it is not, such as an absence of bullying. Most youth described learning something about kindness from their ScoutReach leaders and in ScoutReach meetings. Andre said his leader tells him "if you be nice to others, nice things will come in return," and Leo described learning about being kind from "the code right here... Scout's law....there was some things that...we're supposed to say, like, ten or 12 of them."

Leo also described kindness as being nice to others and "like if anybody gets hurt, you can help them." Sean elaborated further and provided examples of different scenarios in which he thwarts bullying:

There's not really much to tell about how I'm kind or anything, but I treat friends right. I don't stand for bullying, like I don't like when people get bullied. Usually at school if somebody

\footnotetext{
${ }^{1} \mathrm{~A}$ table presenting standardized parameter estimates for the factor loadings in all three models we tested may be obtained from the first author upon request.
} 
is getting bullied, I ask them to leave them alone and they just do it...I help them a lot to teach them that bullying is wrong and it's not cool to bully somebody.

Thus, Sean explained that he is kind to friends by treating them right, and also by standing up to bullies. Other youth also described trying to be nice to their peers who bullied. Tyler said: "There was this boy in my class and for some reason he was just mean to everybody and, I still do not know why, but I started being kind to him and then he came out to be my best friend."

For Tyler and Sean, kindness is not only about being nice to people, but also about tolerating peers who may not always treat others well. Perhaps Tyler and Sean, despite their young age, understand that kindness can go a long way in preventing future bullying incidents. Henry suggested further that these kinds of messages are taught in ScoutReach: "[Cub Scouts teaches] us to, like I say like walk away if something is not going good. And be kind just if somebody's mean to you, just be kind back to them even though they're mean to you." Youth also provided descriptions of kindness that reflected a more explicit value of tolerance. When talking about what kindness means to him, Zachary said ScoutReach teaches, "no matter what color they is you should always be their friends."

Overall, ScoutReach youth appeared to learn about kindness from their leaders and from some of the activities in which they engage during ScoutReach meetings (e.g., learning and reciting the Scout Oath, which includes explicit references to kindness). Although youth seem to learn about and practice kindness in meetings, it was also clear from interviews that kindness is described by these youth as a multidimensional construct, or, to mean many different things (e.g., being nice, sharing, sticking up for one's friends). Youth also described enacting this attribute across contexts, but especially in relationships with peers. Nevertheless, the fact that youth provided so many examples of kindness, largely in response to questions about what they learn in ScoutReach, suggests that this attribute could be associated with their experiences in the program.

Helpfulness. In contrast, helpfulness examples suggest ScoutReach youth engage in this behavior in interactions with non-familial adults, family members, other kids, and even the planet. Jamal said that "this wheelchair lady couldn't move her chair, so I helped her across the street." Lamar said, Like if you're in a house and your mom or your dad or anybody that's in the kitchen or anywhere that needed help, what you can do is go over there and ask them if they need help. If they need help, you can help them.

Andrew said: "I always help my teacher out with everything and sometimes I help other kids with their work." When asked about what, if anything, ScoutReach teaches about helping others, Calvin provided a detailed and context-specific description:

Like it teaches me how to help other little kids, like Wolves and Bears and Tigers. The bigger kids have to show an example to teach the little kids how to be good like them. The little kids, they're just learning, like the Bears. The Webelos are learning too, but the Boy Scouts help everybody, mm-hm, even the staff.

Calvin explained that in ScoutReach, youth practice helping younger Scouts through modeling good behaviors. Importantly, Calvin said that as you advance to Boy Scouts, helpfulness endures because "Boy Scouts help everybody," not just "the little kids." Sean also talked about helping through ScoutReach, specifically, about helping the planet and taking care of nature - a core feature of Scouting curriculum: "Cub Scouts teaches me about taking care of nature, treating it right, that lumberjacking and all that is wrong..." 
For ScoutReach youth, "helpfulness" may be conceptualized as behaviors carried out with people (or things) regardless of your relationship, whereas kindness may be a more friend- or peer-directed behavior. Nevertheless, these excerpts illustrate that youth learn about and practice helpfulness, especially through scaffolding younger peers, while participating in ScoutReach programming.

ScoutReach meetings are held after-school, and all youth enrolled in the program engage in activities together, regardless of age. Therefore, cross-age scaffolding may also be unique to ScoutReach as traditional packs often meet in age-specific groups (i.e. "Dens"), which may limit opportunities for older Scouts to directly assist younger Scouts in program activities.

Hopeful future expectations. In addition to kindness and helpfulness, ScoutReach also seems to be associated with participants' hopeful future expectations and desires to improve their communities. Louis noted his desire to be president when he grows up, and how Cub Scouts helped him develop this goal because he learned "I can be a leader." Sean said, Scouting helps him achieve his goal "[to do something] that can help the world...to be a scientist...[because]...I'm learning a lot to take care of [the] environment..." Thus, what Sean is learning about environmental conservation in ScoutReach is reportedly influencing his career goals and plans to pursue a career that can also help the world.

Enacting change in the community. Many of the participants also described community-level problems that they wanted to help change, and believed could change in the future, such as "housing prices", "littering", and "violence". For instance, Louis said, "The prices for houses [need to be lower] because people can't pay that much", whereas Anthony stated "[people need to] just stop littering..." References to "littering" were the most frequent "problem" described by participants, which supports the idea that ScoutReach may help youth develop environmentally-conscious commitments through program activities. Lamar said,

Because one of the Boy Scout Troops, we had to go somewhere and we helped clean up the area. We swept. There were a bunch of leaves everywhere, trash and all, so we had a bunch of trash bags and started sweeping it up and putting them in there.

In contrast, Zachary said he wanted "to make the world a better place... [so] White people could live with Black people and no matter what they could still be friends." When asked if he learned anything in ScoutReach that "made him think this way," Zachary admitted that it was his leader who said: "no matter what, you can always be friends with White people or Black people." It appears that in addition to messages about being environmentally conscious, ScoutReach youth are discussing challenges they may encounter related to their ethnic minority status and racism, more broadly, through program participation.

Role models. Participants indicated that ScoutReach leaders influenced their development of goals and commitments, and that some leaders even served as their role models. Youth also noted that some of the strong connections they have to ScoutReach influenced who they look up to. Finally, youth discussed having role models who, though not directly involved in ScoutReach, are likely referenced in their discussions with leaders that occur at ScoutReach meetings.

Calvin discussed how his pack leaders and his grandfathers were his role models and that he "looked up to" his grandfathers in particular, "because both of them were Boy Scouts. One was the Webelo first, then the other one was a Bear. My mom's dad was a Bear, and my dad's dad was a Webelo....and they helped each other." Calvin holds his grandfathers in such high regard due, in part, to their former Boy Scout experiences, but also because he knows that his grandfathers helped others. Moreover, Calvin connected his grandfathers' helping behaviors to their ties to Scouting. This example suggests that Calvin may not only value participation in Scouting, such that it influences his 
identification of role models, but also, the attribute of helping. This example also suggests that Calvin associates Scouting with helping others, and sees helpfulness as a character attribute to strive for.

As mentioned above, ScoutReach youth also described wanting to help others in terms of helping Black and White people be friends and live together. In addition, these youth described developing some of these goals through their participation in Scouting and in discussions with leaders. It is possible that these goals are also reinforced by these youth because they consider prominent African American historical figures to be additional role models in their lives. Specifically, when asked about ScoutReach and role models in and outside of the program, Andre responded: "...King- Dr. Martin, and who else? It was a lady... Rosa Parks." He said he looked up to these individuals because "they wanted rights for Black and White, so Blacks could be the same thing as Whites, so we would be treated the same way Whites are treated." Sean also said:

Martin Luther King...Because he believed that even though Blacks and Whites were enemies, he thought we could get along with each other, but it seems like today in some people's minds it doesn't really get along that way... I take [from this] that I want to be a good leader someday, and I want to be awesome like Martin Luther King and make history in the world.

That these participants referenced such role models in their interviews suggests that these figures may come up in their discussions with leaders, or, at the very least, that their discussions with leaders about being friends with White youth, and/or helping Black and White people get along, are reinforced by some of their conversations in ScoutReach.

These conversations, and youth descriptions of their role models may provide ScoutReach participants with a source of hope as they encounter challenges in their communities (e.g., urban city centers with histories of racial segregation), but also goals to strive for as they progress through the Scouting program (for a review of research on associations between goal pursuit, role models, and hopeful future expectations, see Callina et al., 2015).

Tolerance. Having leaders with whom ScoutReach youth can discuss issues related to their ethnic minority status may also be associated with tolerance, an attribute that was reflected in interview responses. Specifically, ScoutReach youth described believing that everyone should be able to join ScoutReach, including boys from different neighborhoods, and even girls. Jamal said that if girls joined Cub Scouts "it's just gonna be the same", and Andrew explained "a'int no difference [if girls joined the program]. It's just a regular human being like we are." Lamar appeared to agree that girls should be allowed in ScoutReach,

Because they might not like Girl Scouts or they might not want to do another program. And then they might see their brothers having fun in Boy Scouts and then they would ask their brother, 'can you ask the Scout leader can I join the Boy Scouts?', and then if the Scout leaders say yes, I think girls should join the Cub Scouts.

Andre echoed these sentiments, stating, "Because the women were not able to do anything the men were. I think women should have a right to join anything."

Calvin suggested ScoutReach may be a program that influences tolerance by providing opportunities for elementary-aged youth to form relationships with students who are different from them, "because everybody can join Cub Scouts, even people we don't know, and they can start turning into your friends, even from different religions."

Finally, Samuel explained that boys from different neighborhoods and religions should be allowed to join Cub Scouts because "it's a lot of fun and it does not cost money to go in." Here Samuel 
illustrated his awareness that the program being free may make it accessible to financiallydisadvantaged youth. He also believed girls should be allowed to join ScoutReach because "we have a girl Cub Scout leader, [and] it will be fun to have a little different ideas once in a while," which suggests Samuel's appreciation of his female Cub Scout leader may translate to positive views of female peers.

\section{Discussion}

Research focusing on the strengths of ethnic minority youth in urban contexts is becoming increasingly necessary given the negative and deficit-oriented portrayal of these youth and their communities in the media and youth development scholarship (Adams-Bass et al., 2014). ScoutReach is an OST program that was explicitly developed to provide skill-building and leadership activities, delivered in traditional BSA programs, to ethnic minority youth from low-SES backgrounds; youth, who also have historically been underrepresented in major OST programs. In this mixed-methods study, character attributes were investigated among youth in ScoutReach, drawing from an individual $\longleftrightarrow$ context conception of character development grounded in RDS metatheory (Lerner \& Callina, 2014). Features of ScoutReach programming that may be linked to these character attributes were also explored. In the sections that follow, we present meta-inferences integrating our understanding of the quantitative and qualitative analyses to align with the mixed-methods approach utilized in the current investigation (Tashakkori \& Teddlie, 2008).

First, this study replicated the previously identified eight-factor character structure with ScoutReach youth, providing preliminary evidence for the appropriateness of the ACCEA measure for use across diverse samples, specifically boys in Scouting, demographically comparable samples of boys and girls who are not in Scouting, and youth of color from low-SES communities participating in ScoutReach programs (Wang et al., 2015b). This finding supports the idea that youth in ScoutReach may experience similar ecological assets in the OST activity context, insofar as those resources that are associated with conceptualizations of character assessed through the ACCEA.

Qualitative content analyses provided more information about potential connections between ScoutReach experiences described in youth interviews, and the character attributes discussed in youth descriptions of these experiences. Findings indicated that ScoutReach youth enact several character attributes assessed quantitatively in their daily lives, and that these attributes may have different and multifaceted meanings for youth in this study. Youth noted various examples of experiences associated with kindness, helpfulness, and hopeful future expectations, and these examples were tied to experiences in ScoutReach.

The diversity in youth responses and descriptions of character attributes has implications for future use of the ACCEA with children. For instance, future researchers may want to include context-specific items to capture not only the meaning youth ascribe to each attribute (e.g., kindness versus helpfulness), but also how different attributes are applied within the setting being examined in a particular study (e.g., OST context), and across settings (e.g., school, peer groups, families). Items asking youth about if and how they help others at home, at school, and in ScoutReach could enhance our understanding of how this attribute develops, and which adults have the strongest influence on the development of this attribute.

Discussion of hopeful future expectations also arose in youth interviews, particularly in descriptions of enacting change in one's community and influential role models. Results underscore that ScoutReach youth are developing such orientations through positive individual $\longleftrightarrow \longrightarrow$ context, and individual $\longrightarrow$ individual, relations in ScoutReach programs (Lerner \& Callina, 2014). Youth 
descriptions of conversations with ScoutReach leaders, and of why they look up to specific role models, including Marin Luther King Jr. and Rosa Parks, suggest that ScoutReach curricula may incorporate references to the accomplishments of prominent African American leaders as a means to positively impact Scouts' hopeful future expectations. Furthermore, youth descriptions of relationships with such role models underscores the importance of increasing access to major OST programs for ethnic-minority youth who may experience adversity (Hurd \& Sellers, 2013). Actual and ideational relationships with such role models could potentially promote hopeful future expectations, which may be crucial during developmental periods where contextual challenges faced by these youth (e.g., experiences of racism, community violence) increase (Swanson et al., 2003). Through interactions with role models, youth increase their likelihood of receiving positive feedback, which in turn, contributes to long-term hopeful expectations and contributions to one's community (Callina et al., 2015).

Another important finding regarding hopeful future expectations was that participants' descriptions frequently referenced race, racism, and negative inter-group relationships between White and Black people. The fact that youth in this study mentioned issues of race when discussing how they wanted to change their communities, and in descriptions of their role models, suggests that these issues are at the forefront of their minds. Importantly, given that our participants are predominantly ethnicminority youth from low-SES communities, it is not entirely surprising that race and racism, as well as inter-group relations along racial lines, are prominent topics in their daily lives and discussed without prompting (Swanson et al., 2003).

Children are aware of race as early as age three, and some children construct positively and negatively valenced associations about different racial groups at young ages (Swanson et al., 2003). As such, it is encouraging that ScoutReach youth may be able to turn to OST program leaders to discuss race-related experiences, which may facilitate important conversations about racism and tolerance. Such conversations may also be one example of how ScoutReach programs are successfully adapting traditional Scouting curricula to positively impact youth and leaders' cultural competence (e.g., Hershberg et al., 2015).

These findings also suggest that engaging in similar conversations about race may be important for youth in traditional Scouting programs, especially given that these youth are typically from White, middle-class backgrounds, and may be less familiar with discussions of race, racism, and topics like the importance of inter-racial friendships, given their majority status (Leman \& Lam, 2008; Margie et al., 2005). Preliminary analyses indicate that discussions of race-related topics have not occurred in interviews conducted with predominantly White, middle-class youth enrolled in traditional Scouting programs. For both ScoutReach youth and boys participating in traditional Scouting packs, such conversations may provide opportunities to develop civic attitudes and skills further aligned with the goals of the larger BSA organization.

Finally, ScoutReach youth appeared to be very tolerant of their peers, which echoed similar descriptions of tolerance noted in prior research (Hershberg et al., 2015). Youth described believing that girls and boys from different neighborhoods and religious backgrounds should be allowed to join Scouts, whereas youth in traditional Scouting packs were more resistant to the notion of including girls in the program. Previous experiences of being excluded from different contexts due to their ethnic-minority, or low-income, status may have contributed to views that ScoutReach is a context where all youth should be accepted. In light of recent debates about exclusionary BSA program policies, and concerns about the outcomes intolerance may promote in youth (Blumenfeld, 2013), future studies should continue to investigate whether tolerance may represent an additional character attribute for youth who have continued experiences of marginalization in the U.S., but who also have 
opportunities to participate in OST programs, like ScoutReach, which may counteract such negative contextual experiences.

\section{Limitations and Future Directions}

Results from this study should be interpreted in light of several limitations. First, data were crosssectional, which prevents a discussion of intra-individual change in descriptions of character attributes and character-related experiences. In addition, these findings may not be generalizable to youth enrolled in other arms of BSA that are similarly targeting hard-to-research youth, specifically rural youth and White youth in low-income communities. Future research needs to encompass a more representative sample of youth who may also be underrepresented in traditional BSA and other highquality OST programs. Such work should strive to incorporate multitrait-multimethod approaches to account for the positivity bias observed in self-report survey measures and the narrow range of responses on item rating scales as suggested by Wang and colleagues (2015a).

In addition, responses to interview questions may have varied due to differences in verbosity among participants. Thus, character attributes not mentioned in interviews may have less to do with their actual existence among participants, and more to do with the kinds of attributes youth could describe most comfortably in interviews. More in-depth qualitative data with older Scouts could enhance findings about character and character-related experiences in ScoutReach. Gathering such data would also allow for a greater exploration of "new" themes that require future validation, including topics related to tolerance, cross-race friendships, and enacting change in one's community.

Finally, despite important findings generated here regarding the inclusive and tolerant views of ScoutReach youth, participants were not directly asked about their views of or experiences with BSA's national policy which, up until the summer of 2015, prevented gay leaders from being involved in the program (R.M. Gates, personal communication, July 27. 2015). Nevertheless, the fact that ScoutReach youth did talk about holding more inclusionary values despite exclusionary BSA policies suggests that ScoutReach may have a positive influence on the development of youth in the program.

\section{Conclusions}

Overall, results from this study have increased understanding about character attributes among ScoutReach youth, and about features of the program that may contribute to these attributes (e.g., scaffolding, receiving character-related messages from leaders, having important conversations during meetings). This work also highlighted important ecological assets that exist among marginalized youth in the U.S., including important role models and, potentially, heightened tolerance toward other youth. This paper is thus, a small contribution to the bourgeoning area of research on character development among America's diverse youth involved in OST programs.

\section{References}

Adams-Bass, V.N., Stevenson, H.C., \& Kotzin, D.S. (2014). Measuring the meaning of black media stereotypes and their relationship to the racial identity, black history knowledge, and racial socialization of African American youth. Journal of Black Studies, 45(5), 367-395.

Bazeley, P., \& Jackson, K. (Eds.). (2013). Qualitative data analysis with NVivo. Thousand Oaks, CA: Sage Publications. 
Blumenfeld, W.J. (2013). Boy Scouts of America: The good, the bad and the (still) highly discriminatory. Huffington Post. Retrieved from http://www.huffingtonpost.com/warren-jblumenfeld/boy-scouts-of-america-the b 3382827.html

Cabrera, N.J. (2013). Society for Research in Child Development Social Policy Report: Positive development of minority children. Sharing Child and Youth Development Knowledge, 2Л2), 1-30.

Callina, K.S., Mueller, M.K., Buckingham, M.H., \& Gutierrez, A.K. (2015). Building hope for positive youth development: Research, practice, and policy. In E.P. Bowers, G.J. Geldhof, S.K. Johnson, L.J. Hilliard, R.M. Hershberg, J.V. Lerner, \& R.M. Lerner, Promoting Positive Youth Development: Lessons Learned from the 4-H Study. (pp. 71-94). New York, NY: Springer.

Creswell, J.W., \& Plano-Clark, V. (2011). Designing and conducting mixed methods research. Thousand Oaks, CA: Sage Publications.

Dawes, N.P., \& Larson, R. (2011). How youth get engaged: Grounded-theory research on motivational development in organized youth programs. Developmental Psychology, 4オ1), 259-269.

Denzin, N.K., \& Lincoln, Y.S. (2005). Introduction: The discipline and practice of qualitative research. In N.K. Denzin \& Y.S. Lincoln (Eds.), The Sage handbook of qualitative research (pp. 1-43). Thousand Oaks, CA: Sage Publications.

Fredricks, J.A., \& Simpkins, S.D. (2012). Supporting ethnic minority youth during the after school hours: The potential of organized activity participation. Child Development Perspectives, 6, 280 - 287.

Gwet, K.L. (2014). Handbook of inter-rater reliability: The definitive guide to measuring the extent of agreement among raters. Gaithersburg, MD: Advanced Analytics, LLC.

Harris Interactive (2005). Values of Americans: A study of ethics and character. Irving, TX: Boy Scouts of America National Office.

Hershberg, R.M., Chase, P.A., Champine, R.B., Hilliard, L.J., Wang, J., \& Lerner, R.M. (2015). "You can quit me but I'm not going to quit you": A focus group study of leaders' perceptions of their positive influences on youth in Boy Scouts of America. Journal of Youth Development. 10(2), (5-30).

Hilliard, L.J., Hershberg, R.M., Wang, J., Bowers, E.P., Chase P.A., Champine, R.B., Buckingham, M.H., Warren, D.J.A., Ferris, K.A., \& Lerner, R.M. (2014). Beginning a life path of honor and duty: Assessing youth character development in cub scouts. Journal of Youth Development, 9(4), 4-46.

Hooper, D., Coughlan, J., \& Mullen, M. (2008). Structural equation modeling: Guidelines for determining model fit. Electronic Journal of Business Research Methods, 6(1), 53-60.

Hsieh, H.F., \& Shannon, S.E. (2005). Three approaches to qualitative content analysis. Qualitative Health Research, 15(9), 1277-1288.

Hurd, N.M., \& Sellers, R.M. (2013). Black adolescents' relationships with natural mentors: Associations with academic engagement via social and emotional development. Cultural Diversity and Ethnic Minority Psychology, 19(1), 76. 
Jang, S.J., Johnson, B.R., \& Kim, Y. (2012). Eagle Scouts: Merit beyond the badge. Institute for Studies of Religion, Baylor University. Retrieved from http://www.baylorisr.org/wpcontent/uploads/Boy-Scouts-Report.pdf.

Johnson, S.K., Hershberg, R.M., Arbeit, M.R., DeSouza, L.M., Callina, K.S., Gutierrez, A.S., Warren, D.J.A., Harris, E.M., Rubin, R.O., Lerner, J.V., \& Lerner, R.M. (2015). Exploring characteristics of young adult men: Initial findings from a mixed methods evaluation of an all-male, character-focused trade school. Journal of Character Education, 10(2), 129-154.

Lareau, A. (2003). Unequal childhoods: Class, race, and family life. Berkeley, CA: University of California Press.

Leman, P.J., \& Lam, V.L. (2008). The influence of race and gender on children's conversations and playmate choices. Child Development, 79(5), 1329-1343.

Lerner, R.M., \& Callina, K.S. (2014). Relational developmental systems theories and the ecological validity of experimental designs. Human Development, 56(6), 372-380.

Lerner, R.M., Lerner, J.V., Bowers, E., \& Geldhof, G.J. (2015).Positive youth development and relational developmental systems. In W.F. Overton \& P.C. Molenaar (Eds.), Theory and Method. Volume 1 of the Handbook of Child Psychology and Developmental Science (7 ${ }^{\text {th }}$ ed.). (pp. 607-651). Editor-in-chief: R.M. Lerner. Hoboken, NJ: Wiley.

Margie, N.G., Killen, M., Sinno, S., \& McGlothlin, H. (2005). Minority children's intergroup attitudes about peer relationships. British Journal of Developmental Psychology, 23, 251-269.

Molenaar, P.C.M., \& Nesselroade, J.R. (2015). Systems methods for developmental research. In W.F. Overton \& P.C.M. Molenaar (Eds.), Handbook of Child Psychology and Developmental Science, Volume 1: Theory and Method (7th ed., pp. 652-682). Editor-in-chief: R.M. Lerner. Hoboken, NJ: Wiley.

Overton, W.F. (2015). Process and relational developmental systems. In W.F. Overton \& P.C. Molenaar (Eds.), Handbook of child psychology and developmental science. Vol. 1: Theory and method (7th ed., pp. 9-62). Editor-in-chief: R.M. Lerner. Hoboken, NJ: Wiley.

Pedersen, S., \& Seidman, E. (2005). Contexts and correlates of out-of-school activity participation among low-income urban adolescents. In J.L. Mahoney, R.W. Larson, \& J.S. Eccles (Eds.), Organized activities as contexts of development: Extracurricular activities, after-school and community programs (pp. 85-109). Mahwah, NJ: Erlbaum.

Polson, E.C., Kim, Y.I., Jang, S.J., Johnson, B.R., \& Smith, B. (2013). Being prepared and staying connected: Scouting's influence on social capital and community involvement. Social Science Quarterly, 94, 758-776.

Richardson, J.B., Brakle, M., \& St Vil, C. (2014). Taking boys out of the hood: Exile as a parenting strategy for African American male youth. In K. Roy \& N. Jones (Eds.), Pathways to adulthood for disconnected young men in low-income communities. New Directions for Child and Adolescent Development, 143, 11-31. 
Satorra, A., \& Bentler, P. (1999). A scaled difference chi-square test statistic for moment structure analysis. Technical Report. University of California, Los Angeles.

Simpkins, S.D., Vest, A.E., \& Price, C.D. (2011). Intergenerational continuity and discontinuity in Mexican-origin youths' participation in organized activities: Insights from mixed-methods. Journal of Family Psychology, 25(6), 814-824.

Swanson, D.P., Spencer, M.B., Harpalani, V., Dupree, D., Noll, E., Ginzburg, S., \& Seaton, G. (2003). Psychosocial development in racially and ethnically diverse youth: Conceptual and methodological challenges in the 21st century. Development and Psychopathology, 15(3), 743-771.

Tashakkori, A., \& Teddlie, C. (2008). Quality of inferences in mixed methods research: Calling for an integrative framework. Advances in mixed methods research, 101-119.

Vandell, D.L., Larson, R.W., Mahoney, J.L., \& Watts, T.W. (2015). Children's organized activities. Handbook of Child Psychology and Developmental Science, 4(8), 1-40.

Wang, J., Ferris, K.A., Hershberg, R.M., \& Lerner, R.M. (2015a). Developmental trajectories of youth character: A five-wave longitudinal study of Cub Scouts and non-Scout boys. Journal of Youth and Adolescence, DOI 10.1007/s10964-015-0340-y.

Wang, J., Hilliard, L.J., Hershberg, R.M., Bowers, E.P., Chase, P.A., Champine, R.B., Buckingham, M.H., Braun, D.A., Gelgoot, E.S., \& Lerner, R.M. (2015b). Character in childhood and early adolescence: Models and measurement. Journal of Moral Education, 44(2), 165-197.

Wothke, W. (2000). Longitudinal and multi-group modeling with missing data. In T.D. Little, K.U. Schnabel, \& J. Baumert (Eds.), Modeling longitudinal and multiple group data: Practical issues, applied approaches and specific examples (pp. 219-240, 269-281). Mahwah, NJ: Lawrence Erlbaum Publishers.

Zimbardo, P.G., \& Duncan, N. (2012). The demise of guys: Why boys are struggling and what we can do about it. New York, NY: TED Conferences, LLC.

(C) Copyright of Journal of Youth Development Bridging Research and Practice. Content may not be copied or emailed to multiple sites or posted to a listserv without copyright holder's express written permission. Contact Editor at: patricia.dawson@oregonstate.edu for details. However, users may print, download or email articles for individual use.

ISSN 2325-4009 (Print); ISSN 2325-4017 (Online) 